\title{
Acquired Factor II Deficiency
}

National Cancer Institute

\section{Source}

National Cancer Institute. Acquired Factor II Deficiency. NCI Thesaurus. Code C131622.

An acquired coagulation disorder characterized by the partial or complete absence of

prothrombin (factor II) activity in the blood. 